\title{
PREVALENSI ASIMETRI FUNGSIONAL PADA MURID SD DAN SLTP TARSISIUS VIRETA TANGERANG USIA 9 - 16 TAHUN
}

\author{
Cathy Kadharmestan*, Maria Purbiati**, Haru S. Anggani*** \\ * PPDGS Ortodonsia Fakultas Kedokteran Gigi Universitas Indonesia \\ ** Departemen Ortodonsia Fakultas Kedokteran Gigi Universitas Indonesia
}

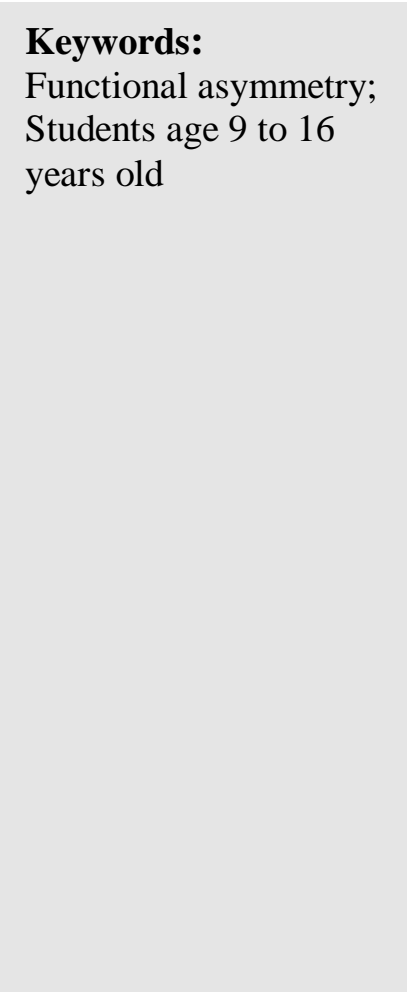

\begin{abstract}
The objectives of this study were to determine the prevalence of functional asymmetry in elementary and junior high school Tarsisius Vireta Tangerang students from 9 to 16 years old, and to determine which age group has the most extensive functional asymmetry. The subjects were grouped based on the development of the first molar until the second molar, as follows: group of age 9 to 11 years old, age above 11 to 14 years old, and age above 14 to 16 years old. Functional examination was done with a modified Castaldi method. The results showed that overall, functional asymmetry was found in 18 out of 306 subjects (prevalence $5.88 \%$ ) who were examined. From the age group of 9 to 11 years old, there were 8 such subjects (7.14\%); from the age group of above 11 to 14 years old, 7 subjects $(6.73 \%)$; from the age group of above 14 to 16 years old, there were 3 subjects (3.33\%). Therefore, the age group of 9 to 14 years old was showing most frequent functional asymmetry. It was also found that most subjects that experienced functional asymmetry, especially in anteroposterior direction, were subjects with class III malocclusion. In general, subjects with functional asymmetry had crowding and premature contact - which could happen at almost any tooth, but mostly at the incisors.
\end{abstract}




\section{Pendahuluan}

Pasien-pasien yang datang untuk mendapatkan perawatan ortodonsia seringkali mempunyai wajah yang asimetri. Jika asimetri wajah yang ditemukan pada pasien ternyata sudah berupa asimetri skeletal, perawatannya akan menjadi lebih sulit karena perawatan ortodontik mungkin perlu dikombinasikan dengan koreksi bedah. Asimetri skeletal dapat disebabkan oleh banyak faktor. Salah satunya dapat berasal dari asimetri fungsional. ${ }^{1-3}$ Schmid, dkk ${ }^{3}$ mengemukakan bahwa $75 \%$ dari asimetri fungsional dapat berkembang menjadi asimetri struktural (skeletal).

Asimetri fungsional adalah asimetri yang terjadi oleh karena adanya pergeseran mandibula ke lateral dan/ atau anteroposterior. Pergeseran letak mandibula tersebut terjadi karena terdapat hambatan oklusi sewaktu gerakan relasi sentris ke posisi interkuspasi maksimum pada saat menutup mulut. ${ }^{1,2,4}$ Asimetri fungsional cenderung disertai dengan adanya asimetri dental (gigit silang posterior unilateral) dan jika tidak dikoreksi sejak dini, sejalan dengan bertambahnya usia bisa mengarah pada terjadinya asimetri skeletal dan gangguan lainnya, seperti pada sendi temporomandibula dan modifikasi pertumbuhan jaringan lunak. ${ }^{1,3-16}$ Asimetri fungsional dapat bermula pada anak-anak. Pertumbuhan dan perkembangan gigi mengalami perubahan. Pada saat terjadinya perubahan itu, hambatan oklusal baik natural maupun iatrogenik dapat terjadi. ${ }^{17,18}$ Secara umum, hambatan oklusal dapat ditemukan pada sekitar $20 \%$ anak-anak berusia 10 tahun atau lebih. ${ }^{19}$

Berdasarkan paparan tersebut di atas, maka sangatlah penting untuk dapat menemukan asimetri fungsional sedini mungkin. Jika dibutuhkan, intervensi secara ortodontik juga dapat dilakukan sedini mungkin, sehingga terjadinya asimetri skeletal oleh karena asimetri fungsional dapat dicegah. ${ }^{20}$

Tujuan penelitian ini adalah untuk mendapatkan prevalensi asimetri fungsional pada murid-murid SD dan SLTP Tarsisius Vireta Tangerang, usia 9-16 tahun dan untuk mengetahui kelompok usia dengan prevalensi terbesar. Penelitian ini juga meninjau aspek lain yang menyertai asimetri fungsional, seperti keadaan lokal gigi-geligi dan gigi penyebab asimetri fungsional. Dengan didapatkannya data-data tersebut, diharapkan para ortodontis dapat meningkatkan kewaspadaannya terhadap asimetri fungsional sehingga waktu perawatan dini dapat ditentukan dan dilakukan perawatan yang tepat sasaran.

\section{Cara Kerja}

Penelitian ini adalah penelitian observasional deskriptif dengan desain potong lintang. Subyek yang berjumlah 306 murid Sekolah Tarsisius Vireta Tangerang dari kelas 3 sampai kelas 9, diambil secara acak stratifikasi dan memenuhi kriteria sebagai berikut; Memiliki ciri-ciri hambatan oklusal (natural dan iatrogenik, termasuk malposisi gigi, gigi berjejal, spacing, pergeseran garis tengah lengkung gigi), dapat berkomunikasi dan diajak bekerjasama dengan baik, tidak sedang menjalani perawatan ortodonti, tidak menderita kelainan TMJ (diketahui melalui kuesioner dan pemeriksaan klinis), dan tidak mengalami asimetri skeletal (1/3 muka tengah dan $1 / 3$ muka atas) yang nyata (Tabel 1).

Tabel 1. Kondisi subyek penelitian berdasarkan kelompok usia.

\begin{tabular}{cccccc}
\hline Kelompok usia & Jumlah awal & $\begin{array}{c}\text { Pakai alat } \\
\text { Orto }\end{array}$ & TMJ & $\begin{array}{c}\text { Asimetri } \\
\text { skeletal }\end{array}$ & $\begin{array}{c}\text { Jumlah subyek } \\
\text { penelitian }\end{array}$ \\
\hline 9-11 tahun & 118 & 2 & 3 & 1 & 112 \\
$>\mathbf{1 1 - 1 4}$ tahun & 107 & 1 & 2 & 0 & 104 \\
$>\mathbf{1 4 - 1 6}$ tahun & 96 & 2 & 4 & 0 & 90 \\
Total & $\mathbf{3 2 1}$ & $\mathbf{5}$ & $\mathbf{9}$ & $\mathbf{1}$ & $\mathbf{3 0 6}$ \\
\hline
\end{tabular}


Tabel 2. Jumlah dan prosentase subyek yang mengalami asimetri fungsional berdasarkan kelompok usia.

\begin{tabular}{lcccc}
\multicolumn{1}{c}{ Kelompok usia } & Asimetri & Tidak Asimetri & Jumlah subyek & $\begin{array}{c}\text { Prosentase } \\
\text { asimetri }\end{array}$ \\
\hline Semua usia & $\mathbf{1 8}$ & 288 & 306 & $\mathbf{5 , 8 8 \%}$ \\
9-11 tahun & 8 & 104 & 112 & $7,14 \%$ \\
$>\mathbf{1 1 - 1 4}$ tahun & 7 & 97 & 104 & $6,73 \%$ \\
$>\mathbf{1 4 - 1 6}$ tahun & 3 & 87 & 90 & $3,33 \%$ \\
\hline
\end{tabular}

Tabel 3. Jumlah dan prosentase subyek yang mengalami asimetri fungsional berdasarkan klasifikasi Angle.

\begin{tabular}{lcccc}
\hline Maloklusi & Asimetri & Tidak asimetri & Jumlah & Prosentase \\
\hline Kelas I & 9 & 188 & 197 & $4,7 \%$ \\
Kelas II & 2 & 74 & 76 & $2,6 \%$ \\
Kelas III & 7 & 26 & 33 & $21,21 \%$ \\
\hline
\end{tabular}

Tabel 4. Jumlah subyek dengan tipe maloklusi tertentu yang mengalami asimetri fungsional berdasarkan kelompok usia.

\begin{tabular}{lcccc} 
Kelompok usia & MO kls I & MO kls II & MO kls III & Jumlah Asimetri Fungsional \\
\hline 9-11 tahun & 2 & 2 & 4 & 8 \\
>11-14 tahun & 5 & 0 & 2 & 7 \\
$>$ 14-16 tahun & 2 & 0 & 1 & 3 \\
Total & 9 & 2 & 7 & 18 \\
\hline
\end{tabular}

Analisis fungsional dilakukan menurut cara Castaldi $^{21}$ yang dimodifikasi, yaitu dengan mencari posisi oklusi sentris terlebih dahulu. Setelah itu, subyek diinstruksikan untuk membuka mulutnya sebesar $\pm 1 \mathrm{~cm}$. Kemudian mandibula subyek dipandu sampai kepada posisi oklusi sentris kembali. Hal ini dilakukan sampai tiga kali. Pergeseran ke arah anteroposterior dinilai berdasarkan perbedaan jarak gigit pada saat relasi sentris dan oklusi sentris. Sedangkan pergeseran ke arah lateral dinilai berdasarkan perbedaan jarak antara garis tengah lengkung gigi atas dan bawah pada saat posisi relasi sentris dan oklusi sentris. Jika pergeseran tersebut lebih dari $1 \mathrm{~mm}$, berarti subyek mengalami asimetri fungsional.

Jika tidak yakin besarnya pergeseran mandibula adalah sebesar $1 \mathrm{~mm}$ atau lebih, pengukuran dilakukan dengan menggunakan penggaris. Selain pencatatan ada atau tidaknya asimetri fungsional, gigi yang menyebabkan prematur kontak, keadaan lokal subyek (gigi berjejal, gigi yang mengalami gigit silang, tipe gigit silang, spacing), dan klasifikasi Angle melalui relasi molar pertama dan pemeriksaan bidigital juga dicatat.

\section{Hasil Penelitian}

Secara umum, prevalensi asimetri fungsional pada murid SD dan SLTP Tarsisius Vireta Tangerang usia 9-16 tahun adalah 5,88\%. Prevalensi terbesar terdapat pada murid usia 911 tahun (Tabel 2).

Berdasarkan klasifikasi Angle, umumnya subyek yang paling banyak menderita asimetri fungsional adalah subyek dengan maloklusi kelas I. Namun menurut prosentase masingmasing kelas maloklusi, asimetri fungsional paling banyak ditemukan pada subyek dengan maloklusi kelas III, terutama pada murid usia 911 tahun dan dalam arah anteroposterior (Tabel 3, 4 dan 5).

Adapun gambaran keadaan gigi-geligi pada subyek dengan asimetri fungsional dapat dilihat pada tabel 6. Sedangkan gigi yang mengalami 
rematur kontak / hambatan oklusal dapat dilihat pada Tabel 7.

\section{Pembahasan}

Penelitian ini dilaksanakan pada sebuah populasi anak dan remaja dengan usia tumbuh kembang rahang dan gigi, karena pada saat itu hambatan oklusal yang dapat menyebabkan asimetri fungsional dapat timbul. ${ }^{17}$ Jika intervensi dini terhadap hambatan oklusal tersebut tidak dilakukan, maka asimetri fungsional dapat berkembang menjadi asimetri skeletal. ${ }^{1,6}$

Berdasarkan pada dua tahap perkembangan oklusi gigi tetap menurut Foster ${ }^{22}$, untuk kepentingan penelitian ini dikelompokkan lagi menjadi tiga kelompok. Kelompok pertama adalah kelompok dengan molar dan insisif yang telah erupsi sempurna, yaitu usia 9,6-10,8 tahun, yang kemudian dibulatkan menjadi usia 9-11 tahun. Kelompok kedua adalah kelompok dengan gigi kaninus dan premolar yang telah erupsi sempurna, yaitu usia 11,6-14 tahun, yang kemudian dibulatkan menjadi usia di atas 11-14 tahun. Kelompok ketiga adalah kelompok dengan gigi molar kedua yang telah erupsi sempurna, yaitu usia $12,9-15,7$ tahun $^{23}$, yang kemudian ditentukan dan dibulatkan menjadi usia di atas 14-16 tahun.

Dari total subyek penelitian yang berjumlah 306 orang, ditemukan 18 orang mengalami asimetri fungsional. Dengan demikian, prevalensi asimetri fungsional pada murid SD dan SLTP Tarsisius Vireta Tangerang usia 9-16 tahun adalah 5,88\%. Prevalensi ini sedikit lebih kecil jika dibandingkan dengan prevalensi yang didapatkan Thilander, yang dikutip oleh GazitRappaport, dkk ${ }^{24}$, yaitu sebesar 6\% - 8\%. Perbedaan prevalensi tersebut mungkin disebabkan oleh karena populasi penelitian dengan kelompok usia yang berbeda. Prevalensi asimetri fungsional pada murid-murid SD dan SLTP Tarsisius Vireta kelas 3 sampai kelas 9 terbesar ditemukan pada kelompok usia 9-11 tahun, yaitu $7,14 \%$. Prevalensi asimetri fungsional pada kelompok usia di atas 11-14 tahun dan usia di atas 14-16 tahun adalah sebesar $6,73 \%$ dan 3,33\%. Kemungkinan hal ini terjadi karena usia 9-14 tahun termasuk dalam tahap usia gigi bercampur sampai gigi permanen tahap awal. Pada tahap-tahap itu masih terjadi perubahan dinamis dari oklusi seiring dengan pertumbuhan rahang dan prosesus alveolaris. ${ }^{19}$ Akibatnya, masalah oklusal dapat timbul sejak saat itu. ${ }^{21}$

Tabel 5. Arah asimetri subyek dengan asimetri fungsional berdasarkan klasifikasi Angle.

\begin{tabular}{lcccc}
\hline \multirow{2}{*}{ Maloklusi } & \multicolumn{3}{c}{ Asimetri Fungsional } & \multirow{2}{*}{ Jumlah } \\
\cline { 2 - 4 } & Anteroposterior & Transversal & A-P \& Transversal & \\
\hline Kelas I & 1 & 6 & 2 & 9 \\
Kelas II & 0 & 2 & 0 & 2 \\
Kelas III & 5 & 0 & 2 & 7
\end{tabular}

Tabel 6. Jumlah dan prosentase dari 18 subyek dengan asimetri fungsional yang disertai dengan gigi berjejal, spacing, 1-2 pasang gigi yang gigit silang, dan gigit silang anterior.

\begin{tabular}{lccccc}
\hline \multirow{2}{*}{$\begin{array}{c}\text { Keadaan gigi- } \\
\text { geligi }\end{array}$} & \multicolumn{3}{c}{ Asimetri Fungsional } & jumlah & Prosentase \\
\cline { 2 - 5 } & Anteroposterior & Transversal & A-P \& Transversal & & \\
\hline Berjejal & 3 & 4 & 3 & 10 & $55,56 \%$ \\
Spacing & 0 & 3 & 0 & 3 & $16,67 \%$ \\
Gigi gigit silang & 1 & 2 & 2 & 5 & $27,78 \%$ \\
Gigit silang & 3 & 0 & 0 & 3 & $16,67 \%$ \\
anterior & \multicolumn{1}{c}{ Total } & & & & 18 \\
\hline
\end{tabular}


Tabel 7. Jumlah subyek dengan asimetri fungsional yang disebabkan oleh prematur kontak gigi tertentu

\begin{tabular}{lcccc}
\hline \multirow{2}{*}{$\begin{array}{c}\text { Gigi Prematur } \\
\text { kontak }\end{array}$} & \multicolumn{3}{c}{ Asimetri Fungsional } & Jumlah \\
\cline { 2 - 4 } & Anteroposterior & Transversal & A-P \& Transversal & \\
\hline $1 / 1$ & 0 & 1 & 1 & 2 \\
$11 / 11$ & 2 & 0 & 0 & 2 \\
$2 / 2$ & 0 & 1 & 2 & 2 \\
$2112 / 2112$ & 3 & 0 & 0 & 3 \\
$3 / 4$ & 0 & 1 & 0 & 2 \\
$4 / 4$ & 0 & 1 & 1 & 1 \\
$4 / \mathrm{IV}$ & 0 & 0 & 0 & 1 \\
$5 / 5$ & 1 & 1 & 0 & 1 \\
$5 / 6$ & 0 & 2 & 0 & 1 \\
$5 / \mathrm{V}$ & 0 & 1 & 0 & \\
$6 / 6$ & 0 & & & 2 \\
\hline
\end{tabular}

Pada kelompok usia di atas 14-16 tahun, kemungkinan gigi sulung yang menyebabkan hambatan oklusal sudah hilang.

Secara umum, asimetri fungsional paling banyak dialami oleh subyek dengan maloklusi kelas I (Tabel 3). Namun berdasarkan jumlah sampel pada setiap tipe maloklusi, persentase asimetri fungsional paling banyak ditemukan pada subyek dengan maloklusi kelas III $(21,21 \%)$, sedangkan pada tipe maloklusi kelas I dan kelas II, asimetri fungsional jarang ditemukan $(4,7 \%$ dan $2,1 \%)$. Temuan ini sesuai dengan hasil penelitian pada asimetri wajah (skeletal) yang dilakukan oleh Severt dan Proffit $^{25}$, serta Achmad (FKG UI, 2005) yang menyatakan bahwa asimetri wajah paling banyak ditemukan pada maloklusi kelas III.

Jika dicermati lebih lanjut dalam Tabel 4 terlihat bahan subyek dengan maloklusi kelas III yang disertai asimetri fungsional paling banyak didapatkan pada kelompok usia 9-11 tahun (4 dari 8 orang). Temuan ini turut mendukung temuan sebelumnya yang menyatakan bahwa kelompok usia dengan asimetri fungsional terbesar adalah pada usia 9-11 tahun.

Pada maloklusi kelas I dan kelas II, subyek dengan asimetri fungsional arah transversal lebih banyak (Tabel 5). Sedangkan pada maloklusi kelas III, asimetri fungsional umumnya terjadi dalam arah anteroposterior. Maloklusi kelas III juga cenderung disertai dengan gigit silang anterior yang merupakan hambatan oklusal pada saat mencapai oklusi sentrik. Gigi yang paling banyak mengalami prematur kontak pada maloklusi kelas III adalah gigi-gigi anterior ataupun beberapa gigi dengan gigit silang. Dengan demikian, temuan ini juga mendukung kejadian maloklusi kelas III yang banyak disertai dengan pergeseran fungsional. ${ }^{26,27}$

Semua hal tersebut di atas menyatakan bahwa asimetri fungsional juga dapat disebabkan oleh faktor skeletal, selain dari faktor lokal. Pola pertumbuhan rahang yang tidak baik (disharmoni skeletal) juga ikut berperan dalam terjadinya hambatan oklusal, yang kemudian mengarah kepada asimetri fungsional. Jika tidak diintervensi, pada akhirnya dapat menjadi asimetri skeletal. ${ }^{3-8}$

Ditinjau dari penyebab lokal asimetri fungsional, ditemukan bahwa prematur kontak dapat terjadi pada hampir semua gigi. Gigi-gigi anterior adalah kelompok gigi yang paling banyak menyebabkan pergeseran fungsional, disusul dengan gigi-gigi premolar. Di antaranya, terdapat dua orang murid pada kelompok usia 911 tahun mengalami pergeseran mandibula oleh karena hambatan pada gigi premolar kedua dengan molar kedua sulung yang sudah goyang dan supraklusi.

Gambaran keadaan lokal yang dapat ditemukan pada subyek penderita asimetri fungsional adalah pada umumnya subyek mengalami gigi berjejal (lebih dari 50\% subyek). Sebagian besar lainnya mempunyai 1 atau 2 pasang gigi yang mengalami gigit silang. 
Hanya sebagian kecil subyek yang mempunyai gigit silang anterior dan spacing.

Pada subyek dengan asimetri fungsional arah anteroposterior, kebanyakan subyek mengalami gigi berjejal dan gigit silang anterior. Sebaliknya, pada asimetri fungsional arah transveral, tidak ditemukan subyek yang mengalami gigit silang anterior. Sedangkan pada asimetri fungsional arah anteroposterior dan transversal, kebanyakan subyek hanya mengalami gigi berjejal dan gigi dengan gigit silang. Semua hal di atas menyatakan bahwa tiap-tiap arah asimetri fungsional mempunyai ciri khas masing-masing.

\section{Kesimpulan}

Prevalensi asimetri fungsional pada murid kelas 3 sampai 9 SD dan SLTP Tarsisius Vireta Tangerang adalah sebesar 5,88\%, dengan kelompok usia 9-11 tahun yang paling banyak mengalaminya, yaitu sebesar $7,14 \%$. Pada kelompok usia diatas 11-14 tahun dan diatas 1416 tahun, prevalensinya sebesar $6,73 \%$ dan 3,33\%.

Prevalensi asimetri fungsional pada subyek berdasarkan tipe maloklusinya adalah sebagai berikut: kelas I sebesar 4,7\%, kelas II sebesar $2,1 \%$, dan kelas III sebesar 21,21\%. Berdasarkan keadaan gigi-geliginya, subyek penderita asimetri fungsional umumnya mengalami gigi berjejal. Sebagian subyek mempunyai satu atau beberapa gigi yang gigit silang, gigit silang anterior, dan spacing.

Kontak prematur atau hambatan oklusi dapat terjadi pada gigi insisif, kaninus, premolar maupun molar pertama, dengan angka kejadian yang paling banyak adalah pada gigi-gigi anterior. Dari seluruh subyek yang diteliti, tidak ditemukan subyek dengan asimetri fungsional yang mengalami gigit silang posterior unilateral.

\section{Daftar Acuan}

1. Bishara SE. Textbook of Orthodontics. USA: W.B. Saunders Company. 2001:300-306, 536$544,561,566$.
2. Joondeph D. Mysteries of asymmetries. Am J Orthod Dentofacial Orthop 2000; 117: 576-9.

3. Schmid W, Mongini F, Felisio A. A computerbased assessment of structural and displacement asymmetries of the mandible. Am J Orthod Dentofacial Orthop 1991;100:19-34.

4. Pinto AS, Buschang PH, Throckmorton GS, Chen P. Morphological and positional asymmetries of young children with functional unilateral posterior crossbite. Am J Orthod Dentofacial Orthop 2001;120:513-20.

5. Pirttiniemi PM. Associations of mandibular and facial asymmetries-A review. Am J Orthod Dentofacial Orthop 1994; 106: 73-7.

6. Lam P, Sadowsky C, Omerza F. Mandibular asymmetry and condylar position in children with unilateral posterior crossbite. Am J Orthod Dentofacial Orthop 1999; 115: 569-75.

7. Malandris M, Mahoney EK. Aetiology, diagnosis and treatment of posterior cross-bites in the primary dentition. Int $J$ Paediatr Dent 2004; 14: 155.

8. Langberg BJ, Arai K, Minerc RM. Transverse skeletal and dental asymmetry in adults with unilateral lingual posterior crossbite. $A m J$ Orthod Dentofacial Orthop 2005; 127: 6-16.

9. Jerrold L, Lowenstein LJ. The midline: Diagnosis and treatment. Am J Orthod Dentofac Orthop 1990; 97: 453-62.

10. O'Byrn BL, Sadowsky C, Schneider B, BeGole EA. An evaluation of mandibular asymmetry in adults with unilateral posterior crossbite. Am J Orthod Dentofacial Orthop 1995; 107: 394400.

11. Binder RE. Correction of Posterior Crossbites: Diagnosis and Treatment. Pediatr. Dent. 2004; 26: 266-72.

12. Nerder PH, Bakke M, Solow B, Begole E. The functional shift of the mandible in unilateral posterior crossbite and adaptation of the temporomandibular joints: A pilot study. Eur $J$ Orthod 1999; 21: 155-6.

13. Cross D, McDonald JP. Effect of rapid maxillary expansion on skeletal, dental and nasal structure: A postero-anterior cephalometric study. Eur J Orthod 2000; 22: 519-28.

14. Hess K, Artun J, Joondeph D, Kennedy DB. Changes in condylar position and occlusion associated with maxillary expansion for correction of functional unilateral crossbite. $\mathrm{Am}$ J Orthod Dentofacial Orthop 1997; 111: 41018. 
15. Myers DR, Barenie JT, Bell RA, Williamson EH. Condylar Position in Children With Functional Posterior Crossbites: Before and After Crossbite Correction. Pediatr Dent 1980; 2: 190-94.

16. Nanda, R. Biomechanics and Esthetic Strategies in Clinical Orthodontics. USA: Elsevier, Inc. 2005: 44-5, 61-2, 69, 100-1.

17. Ash MM dan Ramfjord. Occlusion. 4th ed. USA: W.B. Saunders company. 1995: 50-76, 114-5, 214, 353.

18. Profitt, W.R. Contemporary Orthodontics. $3^{\text {rd }}$ ed. St.Louis: Mosby, Inc.2000: 146, 435-41.

19. Koch G, Modeér T, Poulsen S, Rasmussen P. Pedodontics - a clinical approach. $1^{\text {st }}$ ed. Denmark: P.J. Schmidt, Vojens. 1991: 48, 5053, 56-57, 289.

20. Viazis AD. Efficient orthodontic treatment timing. Am J Orthod Dentofacial Orthop 1995; 108: 560-1.

21. Castaldi CR dan Brass GA. Dentistry for the adolescent. USA: W.B. Saunders company. 1980: 192-218.
22. Foster TD. A Textbook of Orthodontics. $2^{\text {nd }}$ ed. London: Blackwell Scientific Publications. 1982: 54.

23. Welbury RR. Pediatric Dentistry. USA: Oxford University Press Inc. 1999: 12.

24. Gazit-Rappaport T, Weinreb M, Gazit E. Quantitative evaluation of lip symmetry in functional asymmetry. Eur J Orthod 2003; 25: 443-50.

25. Severt TR, Proffit WR. The prevalence of facial asymmetry in the dentofacial deformities population at the University of North Carolina. Int J Adult Orthodon Orthognath Surg 1997; 12 : 171-6.

26. Rabie ABM, Gu Y. Diagnostic criteria for pseudo-class III malocclusion. Am J Orthod Dentofacial Orthop 2000; 117: 1-19.

27. Mergen J, Shelly A, Christensen G, Casko J. Treatment of a class III malocclusion with maxillary constriction and an anterior functional shift. Am J Orthod Dentofacial Orthop 1999; 116: 324-8. 